\title{
Estimativa de um Modelo não Linear para as Exportações Brasileiras de Borracha no Período 1992-2006
}

\author{
Igor Alexandre Clemente de Morais ${ }^{1}$ \\ Adriana Bertoldi \\ Adriana Toledo Mendes dos Anjos
}

\begin{abstract}
Resumo: O objetivo deste artigo é aplicar o mecanismo de correção de erros linear e não linear para encontrar as elasticidades de resposta das exportações do setor de borracha a diversas variáveis. Duas importantes contribuições emergem desta pesquisa. A primeira é o uso da metodologia de mudança de regime markoviano. A segunda está relacionada aos resultados para o setor. Para a curva de oferta, não é possível afirmar a existência do efeito J. Há evidência de assimetria de desempenho entre regimes de queda e crescimento da demanda por exportações, bem como entre a duração desses estados. Isso pode estar refletindo a influência das elasticidades de curto prazo, em especial no caso da renda e dos preços. De forma geral, os resultados apontam que choques negativos têm muito mais poder de desestabilizar o comportamento das exportações do setor no Brasil que choques positivos.
\end{abstract}

Palavras-chave: mudança de regime markoviano, exportações, equação de oferta e demanda.

\begin{abstract}
The goal of this paper is to apply the linear and nonlinear error correction model to supply and demand for rubber exports and find elasticities to several variables. Two major contributions emerge from this research. The first is the use of the methodology of Markovian Switching model. The second is related to the results for the sector. For the supply curve is not possible to affirm the existence of the J effect. There is evidence of asymmetry in performance between states of retraction and growth in demand for exports, as well as between the duration of these states. This may reflect the influence of short-term elasticities, particularly in the case of income and prices. Overall, the results show that negative shocks have much more power to destabilize the exports sector in Brazil than positive shocks.
\end{abstract}

Key-words: Markov Switching Models, exports, supply and demand functions.

Classificação JEL: E32, C22, F14.

1 Professor do Programa de Pós Graduação em Economia Unisinos e economista-chefe da FIERGS. E-mails: imorais@unisinos.br, igor.morais@fiergs.org.br 
Estimativa de um Modelo não Linear para as

Exportações Brasileiras de Borracha no Período 1992-2006

\section{Introdução}

A história econômica brasileira é permeada de eventos que produziram diversos impactos sobre o comportamento das contas externas. A abertura comercial do início da década de 1990 proporcionou uma modificação na dinâmica das importações que, até então, eram reprimidas pelo governo. Apesar da forte demanda interna por produtos importados existente no País nesse período, o grande salto foi verificado a partir de 1995, com a implantação do Plano Real. A estabilidade de preços teve como impacto direto o ganho de renda dos consumidores e, com a apreciação da taxa de câmbio nominal e real, a demanda por importações aumentou².

Outra mudança estrutural importante apontada na literatura da área ocorreu em 1999, com a flexibilização da taxa de câmbio que, de um lado, encareceu os produtos importados e, de outro, representou um incentivo às exportações. Apesar do papel de destaque do câmbio na dinâmica do setor externo brasileiro, como apresentado em estudos de Kannebley (2000), Cardoso et al. (2006) e Morais e Barbosa (2006), a estabilidade macroeconômica ressaltou a importância de outras variáveis, até então relegadas a um segundo plano, na determinação das elasticidades da demanda por exportações. Nesse caso, citam-se cinco fatores que contribuíram para a reversão no quadro externo a partir de 2004: (i) juros internacionais baixos para padrões históricos; (ii) o aumento do preço de vários produtos exportados pelo Brasil; (iii) a valorização cambial; (iv) a redução da volatilidade do câmbio; e (v) um aumento da intensificação da corrente de comércio entre as nações.

No Brasil, as exportações sempre desempenharam papel importante no processo de ajustamento das contas externas e na definição da política macroeconômica. As pesquisas na área estimam curvas de oferta e demanda e suas respectivas elasticidades. Uma das justificativas para se usar essa linha de abordagem empírica é que ela permite uma melhor compreensão dos mecanismos responsáveis pelo desempenho do segmento exportador, além da resposta do mesmo a choques adversos nas variáveis exógenas - ver Engle e Granger (1987), Gregory e Hansen (1996) e Hatanaka (2003), para uma discussão metodológica, e Ribeiro (2006) para uma revisão das aplicações a dados da economia brasileira.

Porém, os diversos estudos aplicados ao agregado das exportações e também a diferentes segmentos não contemplam o setor de borrachas. Como forma de preencher essa lacuna na literatura da área, este trabalho tem como principal objetivo estimar curvas de oferta e demanda por exportações do setor, a partir de dados trimestrais englobando o período de 1992 a 2006. Tal intervalo é embasado em Ribeiro (2006) e Morais e Barbosa (2006), que apontam defasagem

2 Para discussão sobre o processo de abertura comercial brasileira, ver Miranda (2000) e Britto (2002). Morais e Portugal (2005) aplicam um modelo de mudança de regime para a demanda por importações brasileiras e identificam uma mudança estrutural ocorrida no período da abertura comercial. 
de três meses para as variáveis de curvas de oferta e demanda. Além disso, essa periodicidade reduz o grau de variabilidade nos dados e a incidência de quebras estruturais, implicando em resultados mais robustos e consistentes.

O modelo proposto deve ser capaz de captar as relações de curto e longo prazo entre as variáveis e o setor, bem como promover as correções estatísticas ocorridas no período e que geram distorções de medida, como as quebras estruturais. Assim, além do uso do mecanismo de correção de erros linear, comum na literatura da área, também é aplicada a proposta de Krolzig et al. (2000) para identificar a presença de mudança de regime. Ressalta-se que essa é uma importante contribuição para a discussão do tema, haja vista sua pouca aplicação a questões do setor externo no Brasil.

Além desses pontos, outros elementos motivam essa pesquisa. Os resultados das elasticidades podem, em primeiro lugar, ajudar na definição de estratégias direcionadas à dinamização desse mercado. Em segundo, tornam possível verificar o efeito de políticas de incentivo implementadas no País, possibilitando a elaboração de análises prospectivas sobre o comportamento do comércio externo. E, em terceiro, de forma complementar, representam uma contribuição aos agentes ligados ao setor - governo, sindicatos e empresas - na tomada de decisões sobre a produção e a comercialização.

Além da introdução, este trabalho está organizado em mais quatro seções. A segunda seção faz considerações históricas sobre a demanda e oferta de borracha no Brasil e no mundo durante o período 1992 a 2006. Na sequência, são descritos a metodologia e os procedimentos econométricos utilizados. $\mathrm{Na}$ quarta seção, abordam-se os principais resultados estatísticos e, por fim, na quinta, são apresentadas as conclusões.

\section{Demanda e oferta de borracha entre 1992 e 2006}

\subsection{Demanda por borracha}

Inicialmente deve-se entender que a demanda internacional por borrachas, sejam na forma sintética ou natural, acompanha de maneira bastante ajustada o crescimento da produção mundial. A principal razão é que as borrachas são matérias-primas utilizadas em diversos tipos de aplicações industriais ${ }^{3}$. Apesar dessa aparente correlação, é importante analisar separadamente os dois grupos de borrachas - sintética e natural -, uma vez que esses produtos apresentam características distintas.

Da década de 1980 até o ano de 2006, observa-se um declínio na participação do consumo de borracha sintética por parte da indústria mundial. Entre as

3 De acordo com dados do International Rubber Study Group (2009), a taxa média anual de crescimento do consumo de borracha no mundo segue a evolução do PIB. 
razões apontadas para essa perda de espaço, duas merecem destaque. Uma delas diz respeito ao aumento dos custos de produção, uma vez que o produto tem como principal componente o petróleo. A outra é a questão regional relacionada à demanda. No início do século passado, a Ásia se despontou como importante mercado consumidor. Tal cenário, aliado ao fato de a região ser grande fornecedora de borracha natural, acabou por influenciar as decisões futuras de investimento no setor ${ }^{4}$. Outro importante mercado para o produto são os Estados Unidos, mas com foco na indústria de pneus (para uso interno e para exportação) e também na produção de artefatos de borracha ${ }^{5}$.

No Brasil, as empresas do setor de borracha passaram por uma situação delicada nos anos de 1995 e 1996. Uma conjunção de fatores desfavoráveis, como a redução das vendas internas juntamente com a queda de preços, afetou os produtores de borracha sintética. Por outro lado, fabricantes de pneumáticos registraram aumento superior a $250 \%$ na quantidade importada de pneus, incluindo os usados 6 .

Apesar desse cenário, é possível citar diversos resultados positivos após a abertura comercial no Brasil. Entre eles está a retomada do aumento consistente e gradual da produção interna de borracha natural a partir de 1993. Houve, ainda, um fortalecimento dos produtores de borrachas sintéticas que, em vista das dificuldades enfrentadas, reduziram custos e elevaram a produtividade a ponto de permitir a ampliação e a consolidação das vendas nos mercados internacionais.

Por sua vez, a importação de pneus, o mais importante segmento demandante de borrachas, cresceu fortemente a partir de 1992. Esse cenário, porém, começou a ser revertido em 1997, após a Portaria Interministerial no 3 , de 12.09.95, que proibiu a importação de bens de consumo usados ${ }^{7}$.

4 Atualmente, Tailândia e Indonésia são os maiores produtores do mundo, respondendo por $27 \%$ e $29 \%$ da produção total mundial, respectivamente. Burger et al. (2002) fazem uma avaliação dos impactos da crise asiática sobre os preços do produto no mercado de borracha natural a partir de um modelo linear. Ver Hurley (1981) e Gamero et al. (2002) para uma discussão mais detalhada sobre os aspectos históricos da produção e consumo de borracha no mundo.

5 Segundo Morceli (2003), os principais produtores não são os maiores consumidores, o que acaba por potencializar o comércio internacional dessa matéria-prima.

6 Além disso, precisam, ainda, adquirir obrigatoriamente parte de suas necessidades de borracha natural no mercado nacional a preços mais elevados. Isso afeta a competitividade do setor em um contexto de abertura econômica, redução de alíquotas de importação e valorização cambial.

7 Segundo Gamero et al. (2007), o Brasil consome cerca de 250 mil toneladas de borracha natural por ano e produz aproximadamente 90 mil toneladas, sendo o elastômero o segundo item de maior saldo negativo na balança comercial do agronegócio brasileiro. Os gastos com a importação do produto ultrapassaram US\$ 1 bilhão entre 1992 e 2002, com uma média anual de US\$ 98 milhões. 
Os preços da borracha no mercado internacional também são fundamentais na determinação da dinâmica do setor. Tanto a volatilidade quanto as mudanças de patamar médio refletem nas decisões de importação e exportação. A desvalorização do produto em mais de 50\% no final da década de 1990 se, por um lado, contribuiu para controlar gastos com importações, por outro, deprimiu a rentabilidade do setor exportador brasileiro. Ressalta-se que os dados de produção, importação e consumo de borracha natural no Brasil sinalizam a existência de uma demanda muito maior que a oferta. E, nos períodos em que há excesso de demanda, a mesma é ajustada via importações. Porém, em 1994, 1996, 1997 e 2001, identifica-se uma redução no consumo, sem a respectiva contraposição de queda na produção nacional ${ }^{8}$.

Como pode ser visto, apesar dos avanços na produção nacional de borracha natural, o País ainda depende significativamente das importações ${ }^{9}$. Ao mesmo tempo, dado o grau de abertura no setor, a maior participação da produção de borracha no consumo total indica um aumento da competitividade do produto doméstico. Basicamente, são dois os motivos: (i) a criação de uma política de incentivo que colaborou e tem colaborado para o desenvolvimento da atividade no País e (ii) a reversão dos preços internacionais, que voltaram a subir a partir da década de 2000 e beneficiaram exportadores ${ }^{10}$.

\subsection{Oferta de borracha}

A principal fonte de borracha natural do mundo é originária da seringueira. Segundo detalhamento histórico de Samonek (2006), no Brasil, até 1820, eram apenas os povos indígenas que fabricavam artefatos de borracha para uso local. Desde então, a borracha começou a ser utilizada como matéria-prima para uso industrial, impulsionando a economia no País entre os anos de 1820 a 1912. A queda nos preços internacionais e a elevação dos custos de produção, relativamente ao seu cultivo, reduziram a competitividade da borracha extrativa.

Assim, entre 1912 e 1942, as políticas para a borracha, em vez de organizarem o setor produtivo primário, foram direcionadas ao financiamento do setor industrial. Esse cenário representou um incentivo à criação de indústrias de artefatos com foco no consumo interno, já que o setor externo não estava adquirindo a borracha nacional - ver Samonek (2006). No cenário mundial, no

8 De acordo com dados do setor, nos últimos anos, a relação entre produção nacional e consumo oscilou entre um mínimo de $25 \%$ e um máximo de $40 \%$.

9 Ver Gamero et al. (2002) para uma discussão sobre o comportamento da indústria de borracha natural no Brasil no final da década de 1990.

10 Para compreender melhor a demanda de borracha nos países, deve-se considerar, ainda, a produção de pneus nos mesmos, uma vez que a indústria pneumática é a maior consumidora de borrachas, e responsável por cerca de $75 \%$ a $80 \%$ da demanda total. Ver Barlow et al. (1994) para uma descrição sobre a indústria mundial da borracha. 
início do século XX, o Brasil era considerado um importante produtor e com posição de destaque no comércio. Mas, aos poucos, foi perdendo participação nesse mercado. Além disso, a produção nacional não consegue suprir as necessidades da indústria consumidora instalada no País.

Em relação à oferta mundial de borracha, destaca-se que mais de $90 \%$ de toda a produção vem dos países da Ásia (Tailândia, Indonésia, Malásia, Índia, China, Vietnã e outros de menor expressão) e, segundo Morceli (2003), a atual estrutura produtiva sinaliza que tal realidade não deve ser alterada no médio prazo.

Dois fatos foram determinantes para que isso acontecesse: (i) os investimentos feitos na adaptação da borracha ao clima asiático e (ii) os investimentos econômicos na exploração do látex. Atualmente, já aparecem alguns focos importantes de produção também nos países africanos banhados pelo Oceano Atlântico, como Libéria, Camarões e Nigéria. Porém, são mercados produtores distantes dos principais centros consumidores, como a região da Ásia e os Estados Unidos ${ }^{11}$.

A oferta de borracha para a economia brasileira é, em grande parte, proveniente de produtores externos. Mesmo assim, as importações somente são autorizadas após a aquisição compulsória de um percentual das necessidades totais de borracha natural no mercado doméstico. Tal prática protecionista acaba por resultar em diferenciais de preços da ordem de $60 \%$ entre o produto feito no País e o importado ${ }^{12}$.

O setor também passou por importante choque de natureza tributária na primeira metade da década de 1990. As alíquotas de importação de borrachas no Brasil, que eram de 40\% em 1990 tanto para a natural como para as sintéticas, tiveram redução gradual, chegando, a partir de 1995, aos níveis de $12 \%$ para as sintéticas e de $4 \%$ para a natural. O resultado direto foi uma maior concorrência nas empresas produtoras de materiais e artefatos. Assim, já a partir de 1994, o País passou a ser, simultaneamente, grande importador de borrachas sintéticas e exportador em pequena parte, bem como grande importador de pneumáticos. Configura-se, então, um cenário de déficit nas transações comerciais do setor. Mesmo com a queda ou estagnação das vendas internas, as empresas produtoras de materiais e artefatos de borracha realizaram um forte ajuste de modo a elevar a competitividade e permitir uma melhor penetração em mercados internacionais.

11 Em geral, todos os produtos feitos de borracha admitem, em sua composição, a mistura com produto sintético. Enquanto, na média mundial, são utilizados entre $20 \%$ e $40 \%$ de borracha natural em relação ao total, na Índia os produtos contêm $70 \%$ de borracha da seringueira - ver Morceli (2003).

12 As importações estão sujeitas, ainda, ao pagamento de alíquotas de importação de $4 \%$ e 5\% da Taxa de Organização e Regulamentação do Mercado de Borracha (TORMB). 
Diante do exposto, nota-se que a demanda mundial de borrachas cresce de forma significativa no mundo e mais aceleradamente no Brasil, enquanto a oferta mundial cresce proporcionalmente, ou mesmo ligeiramente, inferior ao consumo. Além disso, as diferenças de crescimento no consumo entre os países nos últimos anos foram determinantes para modificar geograficamente a distribuição da oferta. No Brasil, a produção de borracha natural cresce ainda mais lentamente que o consumo doméstico do produto, o que reforça o déficit nacional de borracha natural.

\section{Metodologia}

Estimativas econométricas são úteis para testar hipóteses teóricas com dados reais. Apesar do elevado grau de incerteza e dos possíveis erros de estimação que se incorre ao trabalhar com econometria, essa é uma ferramenta útil para avaliar as respostas que determinadas variáveis fornecem a choques. No processo de investigação das elasticidades de oferta e demanda por exportações, podem ser aplicadas diversas ferramentas econométricas, como os modelos de correção de erros e VAR lineares, equações simultâneas e modelos não lineares, que incorporam mudanças de regime - ver Durbin e Koopman (2001) e Krolzig et al. (2000) para uma discussão detalhada dessas metodologias.

Na literatura da área, há uma tendência clara ao uso de modelos de correção de erros, principalmente em formulações lineares. A justificativa é o trato estatístico adequado que essa formulação permite para séries que possuem raiz unitária e cointegram, sem que, no entanto, se percam informações de longo prazo - ver Engle e Granger (1987) e Hatanaka (2003). Porém, na presença de quebras estruturais, os modelos lineares podem falhar em retratar a verdadeira elasticidade, da mesma forma que nada garante que os parâmetros são estáveis ao longo do tempo - ver Portugal (1993) e Gregory e Hansen (1996). Tal característica induz ao uso de modelos não lineares, como o de espaço-estado ou, então, de mudança de regime.

Neste artigo, optou-se pelo uso de estimativas separadas de curvas de oferta e demanda, seguindo tendência em trabalhos anteriores, como de Burger et al. (2002), Morais e Portugal (2005), Morais e Barbosa (2006) e Ribeiro (2006). Nesse caso, são usados modelos de correção de erros linear e também não linear, este ainda pouco explorado na literatura nacional.

Aolongo do processo de investigação histórica dos fatores que influenciaram as curvas de oferta e demanda por exportações brasileiras, destacam-se os preços do produto exportado, do concorrente no mercado internacional, a taxa de câmbio e a evolução da renda mundial. Porém, trabalhos mais recentes procuraram medir a influência de outros fatores, como o grau de abertura da economia, a volatilidade de preços e os custos de produção - ver Ribeiro (2006). 
686 - Estimativa de um Modelo não Linear para as

Exportações Brasileiras de Borracha no Período 1992-2006

De forma geral, as curvas de oferta e demanda podem ser dadas por:

$$
\begin{aligned}
& q x_{t}^{o}=f\left(p x_{t}, p r_{t}, \sigma P_{t}, c p_{t}, c f_{t}, u_{t} . o p e n_{t}\right)+\varepsilon_{t} \\
& q x_{t}^{d}=g\left(p x_{t}, p w_{t}, p r_{t}, \sigma P_{t}, y_{t}\right)+\zeta_{t}
\end{aligned}
$$

Nas quais as variáveis $q x_{t}^{o}$ e $q x_{t}^{d}$ correspondem à quantidade ofertada e demandada por exportação, respectivamente, representadas na forma logarítimica. A variável $p x_{t}$ é o preço de exportação que, de acordo com Ribeiro (2006), capta movimentos dos preços intra-setoriais, além de apresentar relação com os produtos substitutos. Nesse caso, espera-se uma elasticidade preço-oferta positiva e uma elasticidade preço-demanda negativa.

Estudos sobre demanda por exportações assumem que o exportador encontra condições de absorver as variações ocorridas nos custos de produção no mercado interno sem que, para tanto, seja necessário promover reajustes de preços. Essa hipótese está relacionada ao fato de que, do ponto de vista da curva de demanda, o exportador opera na parte preço-elástica - ver Ribeiro (2006).

A variável $p r_{t}$ representa os preços intersetoriais, medidos pela taxa de câmbio real e que podem ser entendidos como uma medida de competitividade da economia. A expectativa é que as elasticidades câmbio-oferta e câmbio-demanda sejam ambas positivas. $\mathrm{O}$ termo $\sigma p_{t}$ é uma medida de volatilidade dos preços. Nesse caso, usa-se um modelo Garch $(1,1)$, aplicado a todas as medidas de preços: $\sigma p_{t}=\left(\sigma p x_{t}, \sigma p w_{t}, \sigma p r_{t}\right)$.

Como salienta Ribeiro (2006), a volatilidade, quando aplicada para a taxa de câmbio, revela a preferência do exportador a transações ou não com moeda forte. Em relação à curva de demanda, o uso da variável volatilidade tem o intuito de captar o risco que o importador corre ao comercializar um produto com um fornecedor em um país onde há incerteza sobre mudanças nos custos de contrato devido a fortes oscilações na taxa de câmbio. Sendo assim, espera-se que uma maior volatilidade resulte tanto em menor demanda quanto em menor oferta por exportações.

A variável $c p_{t}$ representa os custos relativos à produção, cuja proxy é dada pelo salário médio na indústria, enquanto $c f_{t}$ corresponde aos custos financeiros, dados pela Libor de seis meses. A expectativa é que as elasticidades custo-oferta e custo-demanda sejam ambas negativas. Ressalta-se que o motivo para usar a Libor é que o mercado de crédito no Brasil, durante o período analisado, era pouco desenvolvido, o que implica na existência de custos de financiamentos externos para a transação comercial com o exterior.

Os movimentos cíclicos da economia são modelados a partir da utilização da capacidade instalada $u_{t}$ que também revela a preferência pela oferta de produtos no mercado nacional. Nesse caso, assume-se que o produtor nacional tenha preferência por comercializar em seu país. Assim, a expectativa é que o seu coeficiente, na curva de oferta, seja negativo. Ou seja, para um dado aumento 
de $u_{t}$, as exportações devem diminuir, revelando preferências por vendas no mercado interno.

A capacidade de absorção mundial, ou seja, uma medida da renda ${ }^{13}$, é dada por $y_{t}$. Aqui, como em Ribeiro (2006), essa variável é fornecida pela corrente de comércio $y=\frac{(X+M)}{2}$, em que $X_{t}$ são as exportações e $M_{t}$ as importações totais do país. Espera-se elasticidade renda-demanda positiva. O grau de abertura da economia brasileira ${ }^{14}$ é dado por open $_{t}$, e procura captar, para o exportador, a facilidade de entrada no mercado internacional. Ou seja, na medida em que aumentam as transações comerciais com outros países, a expectativa é que os canais de comercialização, burocracia, entre outros, ficam mais livres. Assim, entende-se que, quanto maior o mercado, maior a quantidade de produtos a serem ofertados. Dessa forma, a expectativa é que elasticidade grau de abertura-oferta seja positiva.

O preço do concorrente no mercado internacional é representado por $p w_{t}$ e, nesse caso, a expectativa é que a elasticidade preço-demanda seja positiva, pois quanto maiores forem os preços dos concorrentes internacionais, maiores devem ser as quantidades demandadas do exportador brasileiro. Por fim, $\varepsilon_{t}$ e $\zeta_{t}$ são os choques exógenos.

Usando a função log-linear, a forma funcional para 1 e 2 pode ser dada por:

$$
\begin{aligned}
& q x_{t}^{O}=\alpha_{0}+\alpha_{1} p x_{t}+\alpha_{2} c p_{t}+\alpha_{3} p r_{t}+\alpha_{4} \sigma p_{t}+\alpha_{5} c f_{t}+\alpha_{6} u_{t}+\alpha_{7} \text { open }_{t}+\varepsilon_{t} \\
& q x_{t}^{d}=\beta_{0}+\beta_{1} p x_{t}+\beta_{2} p w_{t}+\beta_{3} p r_{t}+\beta_{4} \sigma p_{t}+\beta_{5} y_{t}+\zeta_{t}
\end{aligned}
$$

Em que as letras minúsculas representam o logaritmo natural e os coeficientes $\alpha_{i}, i=0, \ldots, 7 \beta_{i}, i=0, \ldots, 5$ são as elasticidades a serem estimadas.

Apesar de estudos na área apontarem para grupos distintos de produtos exportados pela economia brasileira ${ }^{15}$, a diversidade da pauta de exportações e a incidência de choques de natureza macroeconômica contribuem para a existência de diferentes elasticidades de resposta das variáveis de comércio exterior, seja ao longo do tempo, seja entre os vários itens exportados. Na maioria dos trabalhos

13 Dada a estreita relação existente entre o crescimento da demanda por borracha e o crescimento da economia, apontado em International Rubber Study Group (2009), a medida de renda mundial é uma boa referência ao comportamento do mercado consumidor de borracha.

14 Para manter a comparação com Ribeiro (2006), e evitar a influência dos preços internacionais sobre a evolução do comércio exterior brasileiro, usou-se como medida de grau de abertura a variável open ${ }_{t}=\frac{\left(X_{t}+M_{t}\right)}{2}$, em valores reais.

15 Ver Amazonas e Barros (1996), Braga e Rossi (1987), Carvalho e Negri (2000), Morais e Barbosa (2006) e Ribeiro (2006). 
citados, a taxa de câmbio real exerceu forte influência sobre o desempenho do setor externo brasileiro - ver Morais e Barbosa (2006) e Ribeiro (2006).

Conforme Moraes (1986), o impacto estimado de uma desvalorização cambial sobre as importações de produtos competitivos à indústria de transformação (produtos manufaturados), no longo prazo, é de -0,6. Portugal (1993) estimou equações de exportações industriais brasileiras através do mecanismo de correção de erros e investigou a hipótese de instabilidade dos parâmetros. Para a equação de oferta de exportação, a elasticidade câmbio encontrada pelo autor foi de 2,48 no longo prazo e de 1,22 no curto. Em Castro (1998), a elasticidadecâmbio de longo prazo estimada para as exportaçóes totais foi de 0,6 , enquanto para os produtos básicos e manufaturados foi de 0,91 e 1,72, respectivamente; para as exportações de semi-manufaturados, o impacto foi de 1,38. Em Carvalho e Negri (2000), a elasticidade-câmbio de longo prazo para as exportações de produtos agropecuários foi baixa, de 0,12.

Kannebley (2000) estimou o impacto da taxa de câmbio para nove setores exportadores, encontrando evidência de que apenas no setor de peças e outros veículos existe um pass-through tanto no longo prazo quanto no curto prazo. Em todos os demais setores, esse efeito foi nulo. Amazonas e Barros (1996) estimaram equações de oferta e demanda de exportações de produtos manufaturados do Brasil, em que a elasticidade-câmbio no curto prazo foi de 0,64 para o modelo sem tendência e de 0,78 para um modelo com tendência ${ }^{16}$. Na literatura internacional, Soependi (1993) usou um modelo de equações simultâneas com dados entre 1970 e 1990 para estimar a oferta de borracha junto com a demanda externa por importações do produto na Indonésia. $\mathrm{O}$ autor observou que os preços são perfeitamente inelásticos, seja na curva de oferta de exportações ou, então, na demanda por importações. Além disso, notou-se forte influência do comportamento da indústria automobilística sobre o mercado de borracha.

Como pode ser visto, os modelos lineares fornecem informações importantes e úteis para a compreensão da relação entre as variáveis que compõem a oferta e demanda por exportações. Porém, nada garante que seja a melhor representação dessa dinâmica, em especial quando aplicado a dados da economia brasileira. As constantes mudanças de política macroeconômica presenciadas no País, tanto no campo fiscal, monetário ou relacionados ao comércio exterior, produziram instabilidade nos parâmetros - ver Portugal (1993) e Morais e Portugal (2005).

Uma alternativa aos modelos lineares de correção de erros é a proposta de Krolzig et al. (2000), que incorpora a possibilidade de uma variável determinar diferentes regimes, sendo representada por:

16 Apesar de diversos resultados para diferentes grupos de produtos e segmentos de exportação, não há na literatura nacional, até o momento, estimativas de elasticidades de exportação para o setor de borracha, o que inviabiliza a comparação com outros resultados. 


$$
\Delta q x_{t}=\alpha_{\left(s_{y}\right)}+\beta_{\left(s_{i}\right)}\left(y^{\prime} q x_{t-1}\right)+\sum_{i=1}^{t} \Gamma_{i\left(s_{s}\right)} \Delta z_{t-i}+\varepsilon_{t}
$$

em que $\Delta q x_{t}$ é a primeira diferença da quantidade exportada, $\alpha_{\left(s_{i}\right)}$ é a constante do modelo, sujeita aos movimentos de uma variável de regime não observada e estocástica $s_{t} \in(1, \ldots, M)$, $\beta_{\left(s_{i}\right)}$ é o parâmetro de ajuste do modelo de longo prazo e $\Delta z_{t-i}$ é a primeira diferença das variáveis independentes, que pode contemplar tanto o modelo3 quanto o4.

Em 5, $\varepsilon_{\left(s_{i}\right)} \sim N I D\left(0, \sum_{\left(s_{s}\right)}\right)$, ou seja, os resíduos gaussianos também podem ser governados pela variável que é definida pelas probabilidades de transição entre os regimes, $P_{i j}=\operatorname{Pr}\left(s_{t+1}=j / s_{t}=i\right)$ com $\sum_{j=1}^{M} P_{i j}$. Para mais detalhes sobre as características dos modelos de mudança de regime, o processo de estimação e aplicações, ver Hamilton $(1989,1991)$ e Ruud (1991).

\section{Resultados estatísticos}

Alguns procedimentos padrões são aplicados a todos os dados previamente, como a construção de um número índice de mesma base, a dessazonalização pelo método X-12 e a aplicação do operador logarítimo. Depois, foram feitos testes tradicionais de raiz unitária como ADF, NG-Perron, na presença de quebra estrutural, como proposto por Perron (1997), e raiz unitária sazonal - ver Hylleberg et al. (1990). No passo seguinte, tanto para os dados da curva de oferta quanto para a curva de demanda, foram feitos testes de cointegração de Johansen (1988) e de Gregory e Hansen (1996), para identificar a existência de quebra estrutural no vetor de cointegração. A existência de vetores de cointegração conduziu a estimativas de um mecanismo de correção de erros linear e também um não linear ${ }^{17}$. As seções a seguir dividem a análise dos resultados entre a curva de oferta e demanda.

\subsection{Equação de oferta de exportações}

A estimativa da oferta por exportações de borracha é feita tendo como base a hipótese de que os produtores domésticos comportam-se como pricetaker, ou seja, o exportador brasileiro se depara com uma curva de demanda perfeitamente preço-inelástica no curto prazo. Portanto, as modificações nos preços do produto no cenário internacional não produzem respostas imediatas na oferta por parte do exportador, dada a dificuldade em se ampliar a produção no curto prazo.

17 Foram usados os pacotes estatísticos Eviews, RATS e Gauss. Por economia de espaço, não foram reportados os resultados estatísticos. Os mesmos podem ser enviados mediante solicitação aos autores. 
Além disso, a decisão do empresário em ofertar o produto é feita tendo em conta a escolha entre vender no mercado interno ou externo, comportamento esse que pode ser captado a partir da utilização da capacidade instalada do setor. Também é assumido que a quantidade ofertada de borracha pelo exportador brasileiro é uma função da taxa de câmbio real, da volatilidade dos preços e dos custos financeiros e de produção. Essas variáveis estão mostradas nos gráficos 1 ao 4 . Os dados ${ }^{18}$ iniciam-se no primeiro trimestre de 1992 e vão até o quarto trimestre de 2006.

Gráfico 1. - $q x, p x, u c i$.

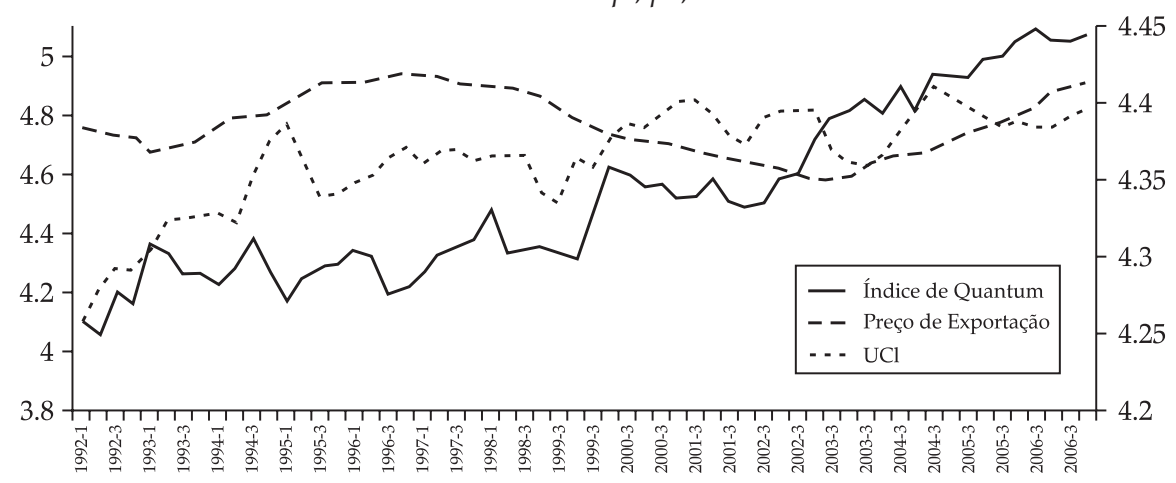

Fonte: Funcex e Ipeadata.

Gráfico 2. - pr, open.

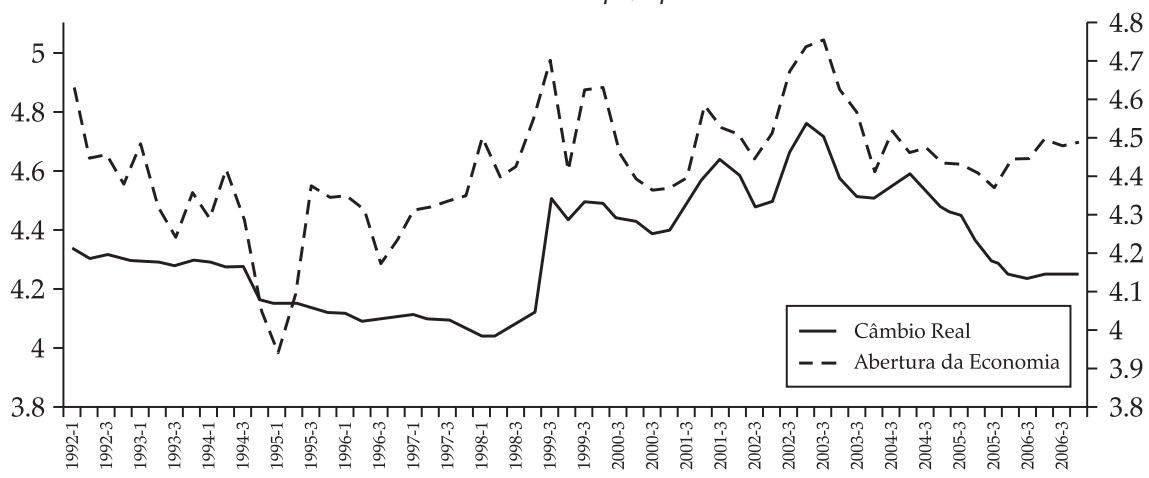

Fonte: Funcex e Ipeadata.

18 Algumas séries não possuem disponibilidade de dados para períodos anteriores ao primeiro trimestre de 1992 e, no momento das estimativas, iam apenas até o último trimestre de 2006. 
Duas características visuais são interessantes no comportamento histórico dos dados: a existência de tendência e as quebras estruturais que podem ter ocorrido nessa e no nível das séries. Os diversos testes de raiz unitária sinalizam que, todas as variáveis, exceto open ${ }_{t}, u_{t}$ e $\sigma p x_{t}$, quando medidas em nível, acusam a presença de raiz unitária. Quando feita a primeira diferença, em relação à equação de oferta, somente a variável $p x_{t}$ não se torna estacionária, característica essa sendo verificada após a segunda diferença.

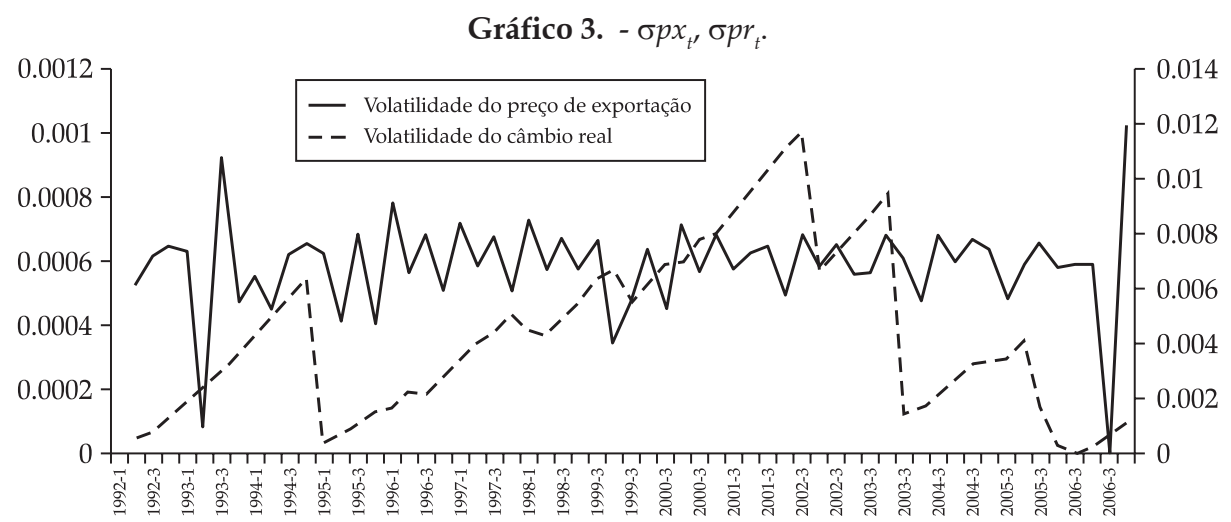

Fonte: Ipeadata, Federal Reserve Board e estimativas pelo modelo Garch $(1,1)$.

Gráfico 4. $c p, c f$.

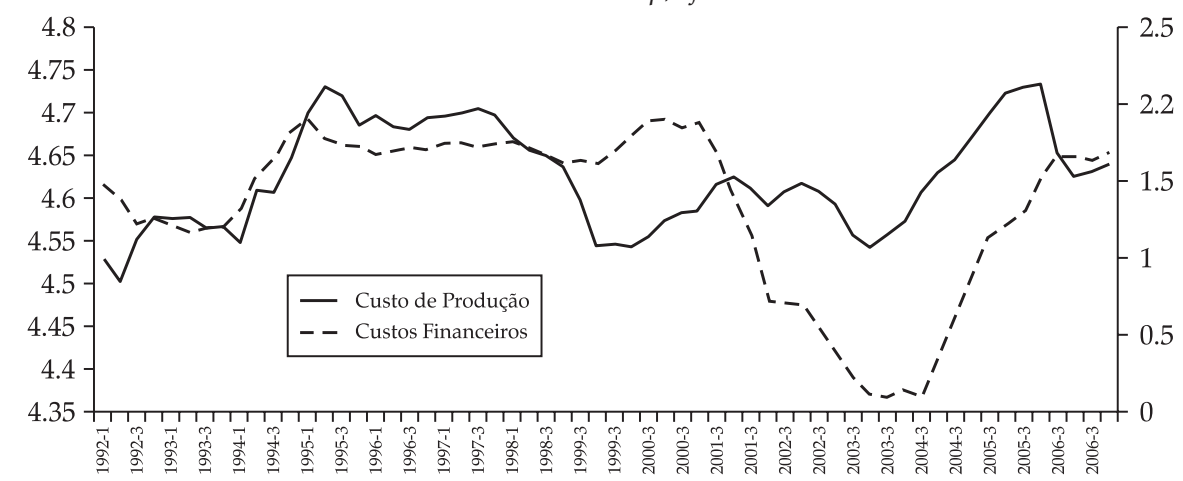

Fonte: Ipeadata, Federal Reserve Board e estimativas pelo modelo Garch $(1,1)$.

Pela inspeção do Gráfico 1, essa série parece ter uma mudança estrutural na tendência, o que demanda o uso de testes mais apropriados para investigar a presença de raiz unitária. A proposta de Perron (1997), que testa raiz unitária na presença de quebra estrutural, foi aplicada às series de dados. Os resultados

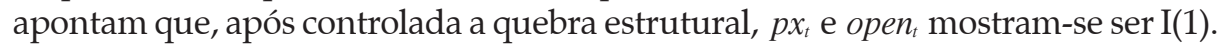


Seguindo a proposta da curva de oferta apresentada em 3, diversas equações lineares de longo prazo foram estimadas com o uso de todas as variáveis. Porém, a partir de critérios de comparação e da significância dos parâmetros, algumas não foram significativas e, usando o método do geral para o específico, foram sendo eliminadas até que se chegasse à melhor equação da oferta de exportação e, ao mesmo tempo, preservasse a significância dos parâmetros. A formulação 6 representa um modelo de longo prazo.

$$
q x_{t}^{0}=\underset{(3,03)}{26,9}-\underset{(0,387)}{1,079} p x_{t}-\underset{(0,27)}{0,333 p r_{t}}-\underset{(6,91)}{56,24 \sigma p r_{t}}+\underset{(0,64)}{7,74 u_{t}}+\underset{(0,165)}{1,018 \text { open }_{t}}+\varepsilon_{t}
$$

A elasticidade preço intersetorial da oferta de exportação no longo prazo, medida pela taxa de câmbio real $(p r)$, e o preço intra-setorial $\left(p x_{t}\right)$ tiveram sinal diferente do esperado, assim como foi verificado para os resultados da utilização da capacidade instalada. Porém, tanto a elasticidade da volatilidade dos preços intersetoriais, quanto o grau de abertura de mercado apresentaram coeficientes em linha com as expectativas apontadas no modelo proposto ${ }^{19}$. Ou seja, maiores volatilidades nos preços resultam em redução da oferta de borracha, da mesma forma que uma maior abertura comercial deve mais que incentivar a oferta ao exterior.

Os resultados de longo prazo apontam características da série de dados que contribuem para viesar o modelo proposto, como a existência de tendência, quebra estrutural e heteroscedasticidade. De acordo com Morais e Barbosa (2006), muitos outros trabalhos demonstraram que variáveis macroeconômicas incluem componentes gerados por choques permanentes, ou seja, as séries são processos integrados com tendência estocástica.

Seguindo a proposta de Johansen (1988), uma alternativa interessante é o uso de uma formulação que represente a cointegração do modelo, combinando variáveis $\mathrm{I}(1)$ de tal forma a constituírem um resultado $\mathrm{I}(0)$. O teste de Johansen (1988) indica que há dois vetores de cointegração. Mas, essa falha em identificar a existência de uma combinação linear de longo prazo na presença de quebra estrutural, pois, assume que o vetor de cointegração é invariante no tempo sob a hipótese alternativa. Ou seja, se existe uma mudança de regime em um momento do tempo no vetor de cointegração, os testes ADF padrão estariam viesados em direção a não rejeição da hipótese nula de ausência de cointegração.

Gregory e Hansen (1996) propõem testes para contornar esse problema, permitindo que o vetor de cointegração apresente uma mudança estrutural em uma data desconhecida, fornecendo uma ferramenta mais confiável na aceitação de uma relação de longo prazo entre as variáveis. Esse foi aplicado às mesmas variáveis usadas no teste de Johansen (1988) e apontou a existência de um vetor de cointegração na equação de oferta, mesmo na presença de quebra

19 As variáveis que representam os custos de produção e financeiros não se mostraram significativas e não foram contemplados em 6. 
estrutural que ocorre possivelmente entre 2002:I e 2003:I. Assim, assumindo a existência de um vetor de cointegração, foi estimado um modelo de correção de erros, representado ${ }^{20}$ pela equação 7.

$$
\begin{aligned}
& \Delta q x_{t}=\underset{(0,008)}{0,02}-\underset{(0,13)}{0,183 \Delta q x_{t-4}}-\underset{(0,08)}{0,32 \Delta \text { open }_{t-1}}-\underset{(0,08)}{0,28 \Delta \text { open }_{t-2}} \\
& -\underset{(0,08)}{0,183 \Delta \text { open }_{t-3}}-\underset{(0,42)}{0,929 \Delta p x_{t-2}}+\underset{(0,02)}{0,048 \varepsilon_{t-1}}
\end{aligned}
$$

O coeficiente da velocidade de ajuste do modelo é 0,048 , ou seja, em torno de $4,8 \%$ dos desequilíbrios são corrigidos a cada trimestre. Na presença de choques no preço internacional do produto, na taxa de câmbio real e no grau de abertura da economia, ocorre um ajuste da oferta por borracha que é relativamente muito pequeno. Tal resultado sinaliza a baixa resposta do setor a mudanças no cenário econômico. Outros trabalhos realizados na área, para outros setores brasileiros, encontram coeficientes de ajuste mais elevados. Portugal (1993), para produtos industriais, apontou coeficiente de 0,22 e, Morais e Barbosa (2006), para as exportações de calçados, encontrou 0,539.

A partir da análise dos coeficientes em 7, observa-se que a abertura comercial apresenta uma elasticidade diferente da esperada. Porém, os coeficientes são significativos e sinalizam impactos prolongados sobre a decisão de oferta, estendendo-se para três trimestres. Esse resultado pode refletir a característica desse setor, que não consegue atender à demanda interna e, além disso, sofre forte concorrência de competidores internacionais no mercado nacional. Sendo assim, não se pode afirmar que a abertura da economia deixa de afetar a decisão de exportação. Porém, esse impacto mostrou-se contrário do esperado.

A elasticidade preço-oferta é alta, indicando que modificações no preço internacional impactam de forma negativa na oferta de exportação. Também um resultado diferente do esperado. Além disso, quando se tem um choque cambial, dada a rigidez dos contratos, a expectativa é que os efeitos sobre as exportações ocorram no longo prazo. Ou seja, há um processo lento de ajuste do mercado a esse novo patamar do câmbio. Esse fenômeno é conhecido na literatura como "efeito em J". No caso em questão, essa característica não se mostrou evidente na oferta de exportação de borracha. Ou seja, no curto prazo, a desvalorização cambial não produz impactos sobre a oferta de exportações. Morais e Barbosa (2006) investigaram a oferta de exportações de calçados e encontraram essa evidência, assim como Cardoso et al. (2006). Já Moura e Silva (2005) refutam esse resultado para a balança comercial brasileira.

20 Aqui também foi usado o procedimento de investigação do geral para o específico, ou seja, estimando um modelo amplo e, a partir de eliminação das variáveis não significativas e dos critérios de comparação, chega-se à formulação final. 
694 - Estimativa de um Modelo não Linear para as

Exportações Brasileiras de Borracha no Período 1992-2006

\subsection{Equação de demanda por exportações}

Apesar da demanda por determinado tipo de produto poder ter a influência de diversos fatores, no presente estudo, investigou-se o comportamento das variáveis descritas em 4 . Ou seja, movimentos na renda, aqui definida como absorção externa, no preço do produto e de um substituto, da taxa de câmbio, além de uma medida de risco na importação, que é a volatilidade dos preços. Os Gráficos 5 e 6 ilustram o comportamento dessas variáveis ${ }^{21}$.

\section{Gráfico 5. - y, pw.}

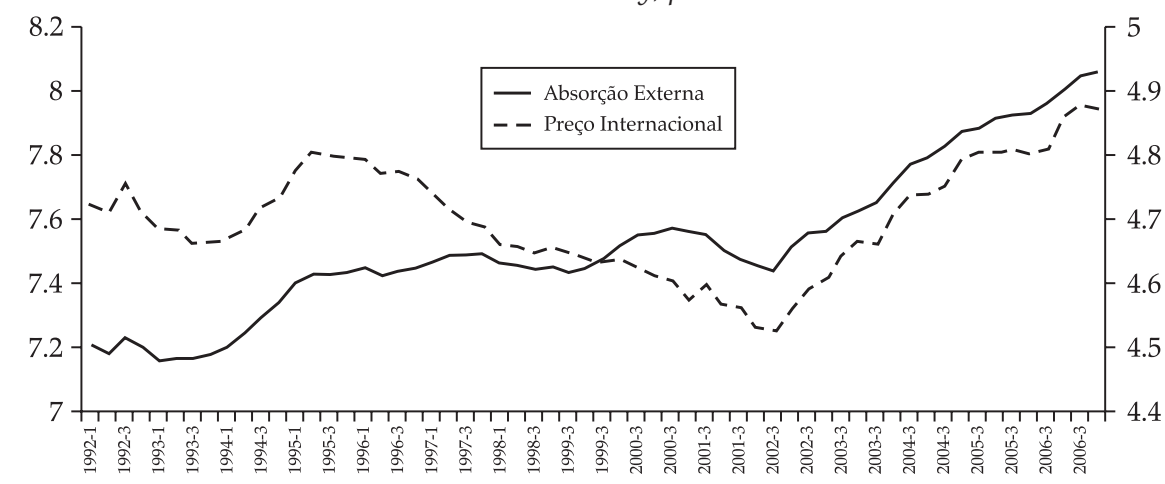

Fonte: Ipeadata e FMI.

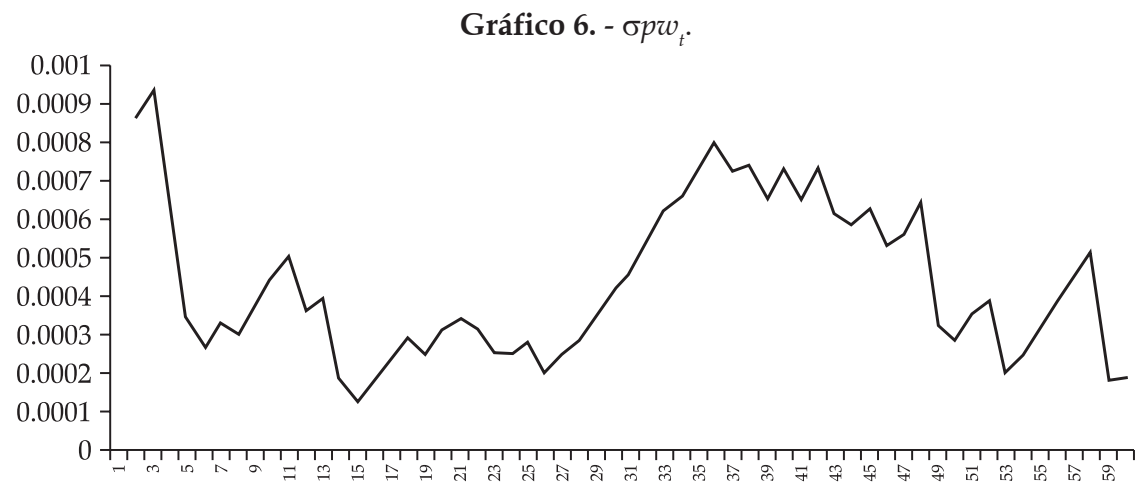

Fonte: Ipeadata e FMI.

Seguindo a metodologia do geral para o específico, foram testadas várias formas que pudessem representar a demanda por exportações de borracha no

21 As mesmas são número índice, dessazonalizadas e aplicadas ao operador logarítimo. A variável preço do produto, quantidade exportada e taxa de câmbio foram ilustradas na seção anterior. 
longo prazo. Após a exclusão de variáveis não significativas do ponto de vista estatístico e do uso de critérios de comparação, selecionou-se a equação 8:

$$
q x_{t}^{d}=\underset{(1,32)}{3,27}-\underset{(0,20)}{1,34 p} x_{t}-\underset{(0,11)}{0,25 p r}+\underset{(0,04)}{1,17} y_{t}-\underset{(60)}{132 \sigma p} w_{t}+\varepsilon_{t}
$$

Todas as elasticidades, à exceção da intersetorial, que mede a competitividade do setor, tiveram o sinal como esperado. A elasticidade preço-demanda é maior que a unidade, mostrando a sensibilidade dos consumidores a variações no preço do produto brasileiro. Também há uma forte relação entre aumentos de renda mundial, medida por $\left(y_{t}\right)$, e a demanda por exportações de borracha, da mesma forma que a volatilidade nos preços internacionais prejudica essa demanda. Tais resultados não deixam evidências claras de que o Brasil seja um país pequeno no mercado consumidor de borracha. Ressalta-se que a hipótese de país pequeno se confirma na alta elasticidade renda-demanda e na infinita elasticidade-preço.

Os testes de raiz unitária sinalizam que praticamente todas as variáveis de demanda são não estacionárias em nível e estacionárias em primeira diferença, mesmo quando considerada a presença de quebra estrutural a partir do teste de Perron (1997). A exceção fica restrita às variáveis que captam os movimentos da volatilidade dos preços, que são $I(0)$.

A análise do teste de cointegração de Johansen (1988) indica que, pelo teste $\left(\lambda_{\text {(traco) }}\right)$, há dois vetores de cointegração, ao passo que, pelo teste $\lambda_{\text {(maximo) }}$, não há sinalização de existência de vetor de cointegração. A aplicação do teste de Gregory e Hansen (1996), sob a hipótese alternativa de quebra estrutural no vetor de cointegração, aponta a existência de uma relação de longo prazo entre as variáveis da equação de demanda ${ }^{22}$, tanto para o teste que considera a mudança de regime no nível, quanto na tendência.

Assumindo a hipótese de pelo menos um vetor de cointegração, como indicado pelos testes, é possível construir um modelo que preserve as relações de curto e longo prazo, como o mecanismo de correção de erros linear. Partindo do método geral para o específico e testando diversos modelos chega-se à equação 9:

$$
\begin{aligned}
& \Delta q x_{t}^{d}=\underset{(0,01)}{0,018}+\underset{(0,16)}{0,23 \Delta p r_{t-1}}+0, \underset{(0,15)}{36} \Delta p r_{t-3}+0 \underset{(0,38)}{20} \Delta y_{t-2}-1, \underset{(0,57)}{10 \Delta} y_{t-3} \\
& +1, \underset{(0,69)}{\Delta p} w_{t-3}-0, \underset{(0,10)}{238 \varepsilon_{t-1}}
\end{aligned}
$$

No curto prazo, a variável preços de exportação não foi significativa. Porém, nota-se uma relação entre a demanda e o comportamento dos preços a partir da elasticidade-preço da borracha no mercado internacional, resultado tal como esperado. Assim, aumentos dos preços internacionais $(p w)$ com defasagem de três trimestres resultam em maior demanda por exportações de borracha

22 Nesse caso, o vetor considerado é dado por ( $q x, p x, p w, p r, y)$. 
brasileira. As estimativas para a elasticidade câmbio-demanda tiveram o sinal esperado nos três trimestres. Portanto, desvalorizações na taxa de câmbio real aumentam a competitividade da borracha brasileira no cenário nacional, com impactos positivos sobre a demanda pelo produto.

A elasticidade renda da demanda no curto prazo, medida pelo coeficiente de $\left(y_{t}\right)$, tem uma dinâmica interessante. Em um primeiro momento, o crescimento da capacidade de absorção internacional causa impactos positivos sobre a exportação de borracha, com uma defasagem de dois trimestres. Porém, ao final de três trimestres, essa se torna negativa, superando a elasticidade do segundo trimestre ${ }^{23}$.

O coeficiente da velocidade de ajuste do modelo foi de 0,238 , demonstrando que em torno de $24 \%$ dos desequilíbrios promovidos por choques nas variáveis são corrigidos a cada trimestre. Tal resultado está em linha com o encontrado por Portugal (1993), quando da estimativa para demanda por produtos industriais, de $-0,2$, e por Morais e Barbosa (2006), para a demanda por calçados, de $-0,38$.

Como forma de complementar esses resultados, foi testado um modelo não linear, no formato da equação 5. Conforme apontado na literatura da área, em especial em Hansen (1992) e Hamilton (1996), a variável de estado que irá governar o movimento dos dados é desconhecida. Dessa forma, não se pode determinar, a priori, o número de regimes existentes. Nesse sentido, foram estimados diversas formulações MS(k)-VEC(1), em que $k=2,3$, supondo mudança de regime na média, no intercepto, no componente autoregressivo e também na variância. É feita uma análise dos critérios de comparação, como Akaike, Hanna-Quinn e Schwarz, além do teste de razão de verossimilhança para verificar se o modelo é não linear.

Os resultados indicam que todas as formulações apresentam características não lineares, uma vez que o teste LR rejeita a hipótese nula de linearidade. Além disso, comparando entre os mesmos modelos porém, com números de estados diferentes, selecionam-se aqueles com $k=2$. Em alguns casos, as formulações com três estados não apresentaram convergência, resultado comum devido à complexidade no processo de estimação - ver Hamilton (1996). A Tabela 1 mostra os resultados para diferentes propostas de MSM(2)-VEC(1) da curva de demanda. Como pode ser visto, o modelo 4 é o que apresenta todos os coeficientes significativos, sendo aqui escolhido para análise.

23 Um teste de igualdade de coeficientes sinaliza pela não rejeição da hipótese nula de que os coeficientes são iguais, com p-valor $=0,09$. 
Tabela 1. Resultados para o Modelo MSM(2)-VEC(1).

\begin{tabular}{lcccc}
\hline & Modelo 1 & Modelo 2 & Modelo 3 & Modelo 4 \\
\hline$\mu_{1}$ & $-0,035(0,007)$ & $-0,029(0,007)$ & $-0,029(0,007)$ & $-0,029(0,007)$ \\
$\mu_{2}$ & $0,078(0,008)$ & $0,081(0,008)$ & $0,081(0,009)$ & $0,081(0,009)$ \\
$\Delta q x_{t-1}$ & $0,177(0,07)$ & $0,175(0,07)$ & $0,181(0,07)$ & $0,174(0,07)$ \\
$\Delta p x_{t}$ & $-1,72(0,244)$ & $-1,83(0,255)$ & $-1,72(0,262)$ & $-1,73(0,267)$ \\
$\Delta p x_{t-1}$ & $0,66(0,241)$ & $0,60(0,262)$ & $0,63(0,281)$ & $0,58(0,260)$ \\
$\Delta y_{t}$ & $0,793(0,29)$ & $0,653(0,19)$ & $0,673(0,206)$ & $0,641(0,194)$ \\
$\Delta y_{t-1}$ & $0,136(0,272)$ & $-0,06(0,20)$ & $-0,08(0,21)$ & - \\
$\Delta p r_{t}$ & $-0,206(0,06)$ & $-0,229(0,07)$ & $-0,230(0,07)$ & $-0,235(0,07)$ \\
$\Delta p r_{t-1}$ & $-0,04(0,06)$ & $-0,08(0,06)$ & - & - \\
$\Delta p w_{t}$ & $-0,202(0,337)$ & - & - & - \\
$\Delta p w_{t-1}$ & $-0,426(0,33)$ & - & - & - \\
$\varepsilon_{t-1}$ & $-0,71(0,07)$ & $-0,696(0,08)$ & $-0,716(0,08)$ & $-0,713(0,08)$ \\
$p_{11}$ & 0,773 & 0,765 & 0,772 & 0,773 \\
$p_{12}$ & 0,609 & 0,591 & 0,598 & 0,593 \\
Akaike & $-2,60$ & $-2,64$ & $-2,64$ & $-2,68$ \\
H-Q & $-2,39$ & $-2,46$ & $-2,48$ & $-2,53$ \\
Teste LR & $14,5 \chi_{(1)}^{2}=0,00$ & $12,8 \chi_{(1)}^{2}=0,00$ & $11,43 \chi_{(1)}^{2}=0,00$ & $11,36 \chi_{(1)}^{2}=0,00$ \\
\hline
\end{tabular}

* Teste de linearidade. Em parênteses o desvio padrão.

A despeito da diferença de variáveis utilizadas, há pouca modificação no valor dos coeficientes entre os modelos da Tabela 4.1. No regime 1, caracterizado por períodos de queda da demanda por exportações de borracha, tem-se que a quantidade exportada apresenta uma taxa média de $-2,9 \%$ ao trimestre. Porém, quando o setor se depara com o regime 2, aqui definido como de expansão da demanda, o crescimento médio das exportações da quantidade de borracha é de $8,1 \%$. À exceção da elasticidade dos preços intersetoriais $\left(p r_{t}\right)$, todos os demais coeficientes estimados possuem sinal como esperado. A elasticidade preço de exportação da demanda é negativa e, mesmo sendo verificado um resultado positivo após um trimestre, o mesmo não é suficiente para reverter o impacto da queda da demanda devido ao aumento de preços.

A elasticidade renda-demanda, medida por $\left(y_{t}\right)$, é positiva, revelando que os consumidores de borracha no cenário internacional reagem de forma positiva a aumentos de renda, mas com impacto menor que a unidade. O coeficiente que mede a velocidade de ajuste do modelo a choques de longo prazo é relativamente alto, revelando que cerca de $71 \%$ são corrigidos a cada período. Ressalta-se que esse valor é bem superior ao encontrado pelo modelo linear e também em outros estudos para diferentes setores.

As estimativas das probabilidades de transição indicam resultados interessantes. A probabilidade de se estar em um regime de expansão da demanda e assim permanecer, dado por $p_{22}=0,59$, é menor que a probabilidade de se 
estar em um regime de queda da demanda e nesse permanecer, $p_{11}=0,77$. Essa estimativa conduz a uma duração do regime de expansão da demanda de 2,4 trimestres, contra uma duração do regime de queda estimada em 4,4 trimestres. Ou seja, períodos de queda da exportação costumam ser mais pronunciados e demorados que regimes de expansão. O conjunto de Gráficos 7 mostra os momentos em que se caracterizam as probabilidades de se estar em cada regime.

Gráfico 7. Probabilidades estimadas - MSM(2)-VEC(1).
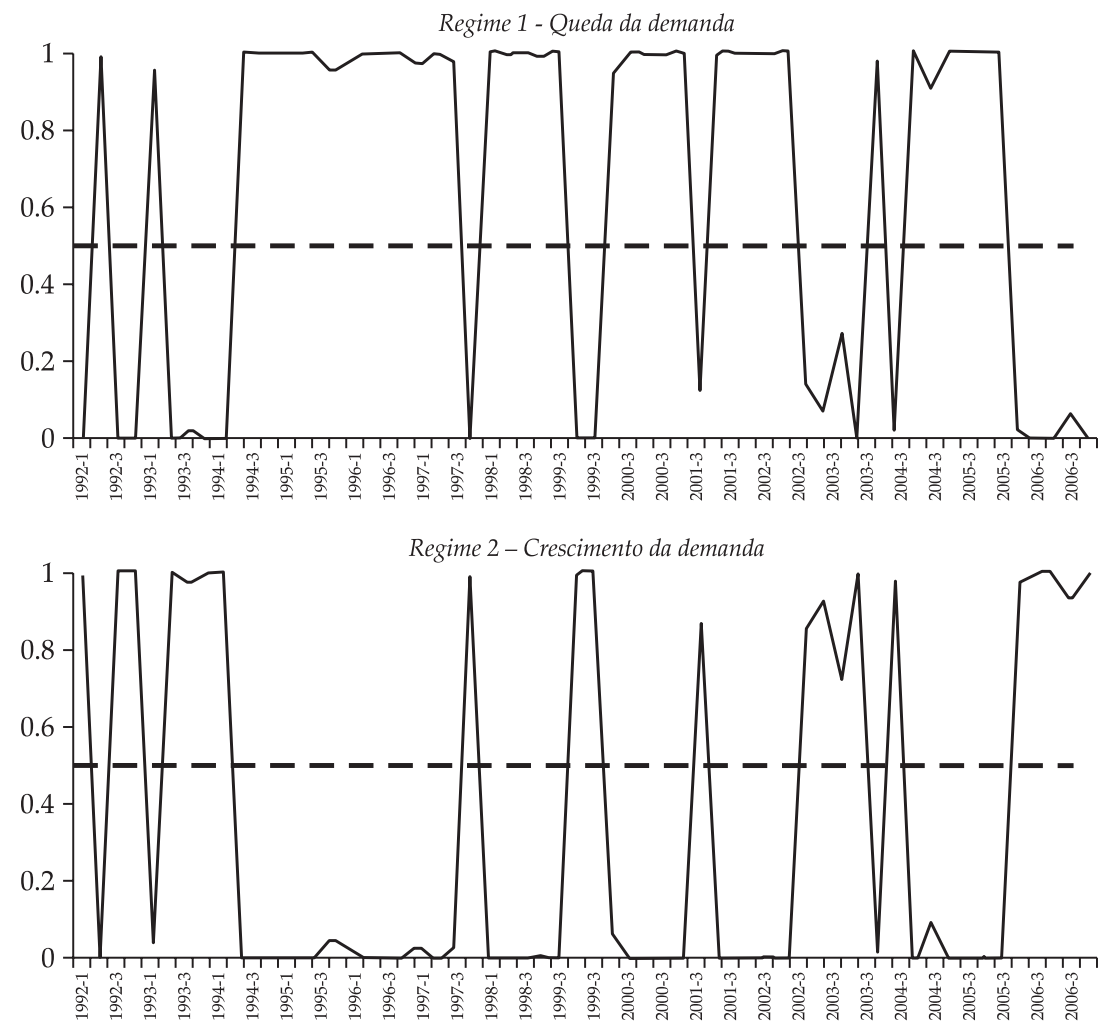

O período mais longo em que se pode observar o regime 1, ou seja, retração nas exportações, ocorre entre 1994-IV e 1997-IV, com um total de 13 trimestres consecutivos. Esse resultado pode estar refletindo a perda de competitividade do produto nacional com a valorização cambial e um fraco desempenho da absorção externa. Por outro lado, a mais longa duração do regime de crescimento da demanda por exportações de borracha é verificada entre 2005-IV e 2006-IV, coincidindo com o cenário conjuntural de expansão do PIB mundial. 


\section{Conclusões}

Diversas pesquisas na área de comércio exterior realizadas no Brasil apontaram para a relevância de variáveis como taxa de câmbio, grau de abertura da economia, renda e preços na determinação da dinâmica das exportações e importações. Porém, a abordagem econométrica de curvas de oferta e demanda por exportações não havia sido aplicada ao setor de borracha.

A partir de dados do primeiro trimestre de 1992 ao último trimestre de 2006, este artigo aplicou o mecanismo de correção de erros linear e não linear para encontrar as elasticidades de resposta das exportações do setor de borracha ao movimento de diversas variáveis. Duas importantes contribuições emergem desta pesquisa. A primeira refere-se ao uso da metodologia de mudança de regime markoviano para caracterizar as elasticidades, um procedimento ainda pouco usado na literatura da área. A segunda está relacionada aos resultados dessas elasticidades.

$\mathrm{Na}$ curva de oferta de exportações, a abertura comercial apontou sinal contrário ao esperado na literatura porém, estatisticamente significativo e com impactos que se estendem por três trimestres. Esse resultado pode estar refletindo a característica do setor, que não consegue atender à demanda interna e, além disso, sofre forte concorrência de competidores internacionais no mercado doméstico. $\mathrm{O}$ sinal da elasticidade preço-oferta também veio diferente do esperado na literatura, o que prejudica a interpretação econômica do modelo. Além disso, como não há evidência de impactos da desvalorização cambial sobre a quantidade ofertada no curto prazo, não se pode afirmar a existência do "efeito J" na curva de oferta. Os testes estatísticos não permitiram a estimativa de um mecanismo de correção de erros com mudança de regime.

O coeficiente de ajuste do modelo a desequilíbrios no longo prazo é pequeno, tanto em termos absolutos quanto comparado com os resultados encontrados em estudos aplicados a outros produtos e setores da economia. De forma geral, apenas 4,8\% desses desequilíbrios são corrigidos a cada trimestre.

Os testes aplicados para a curva de demanda permitiram estimar um mecanismo de correação de erros linear e outro não linear. Em todas as formulações propostas, o teste de razão de verossimilhança rejeita a hipótese nula de linearidade em favor dos modelos não lineares, sendo selecionada a formulação MSM(2)-VEC(1). Porém, algumas diferenças de resultado emergem. No caso da taxa de câmbio, o modelo linear encontra uma elasticidade de impacto que se estende por três trimestres. Apesar de valor pequeno, tem sinal como esperado na literatura. Já nas estimativas não lineares, a elasticidade-câmbio é de curto prazo e com sinal diferente do esperado.

A dinâmica da elasticidade renda-demanda também difere entre as duas estimativas, com o modelo não linear sinalizando para impactos apenas no curto prazo. Seu valor é pequeno, e implica que as exportações do setor sofrem poucos impactos do crescimento da renda mundial. Isso pode estar refletindo o pouco grau de abertura do setor. 
A elasticidade preço internacional-demanda foi significativa no modelo linear, com sinal positivo, tal como esperado na literatura, coeficiente maior que a unidade e com impactos de mais longo prazo (cerca de três trimestres). $\mathrm{O}$ resultado pode estar atrelado à forte influência que o movimento de preços teria sobre as exportações brasileiras do produto. Porém, no modelo não linear, esta não foi significativa. Em contraposição, torna-se importante o movimento de preços das exportações do produto nacional, em especial no curto prazo, com uma elasticidade preço-demanda negativa e elevada.

O coeficiente que mede a velocidade de ajuste do modelo a choques nas variáveis também difere entre a estimativa linear e não linear. No primeiro caso, observa-se que cerca de $23 \%$ dos desequilíbrios são corrigidos a cada trimestre, resultado em linha com os estudos aplicados para dados de outros segmentos no Brasil. Já no modelo não linear, os resultados apontam para um ajuste mais rápido, da ordem de $71 \%$ a cada trimestre.

Outros resultados interessantes fornecidos pelo modelo de mudança de regime se referem às probabilidades de cada estado. Quando o setor se encontra em um cenário de queda das exportações, essa tem uma duração média estimada de 4,4 trimestres com uma retração da ordem de $2,9 \%$ por trimestre. Por outro lado, em períodos de expansão, essa é mais intensa, com média de $8,1 \%$ ao trimestre, embora tenha uma duração mais curta, de 2,4 trimestres, em média. Ou seja, as estimativas sinalizam para uma dinâmica no setor onde há assimetria de desempenho entre regimes de queda e crescimento das exportações, bem como entre a duração desses estados. Um resultado que pode estar refletindo a influência das elasticidades de curto prazo, em especial no caso da renda e dos preços.

Essa assimetria também se faz presente nas probabilidade de transição. A probabilidade de o setor, estando em um cenário de queda da demanda por exportações e assim permanecer, é maior que a probabilidade de se encontrar em um cenário de crescimento e nele permanecer. De modo geral, os resultados apontam que o setor exportador no Brasil se depara com fragilidades e que choques negativos têm muito mais poder de desestabilizar o comportamento das exportações que choques positivos. A partir dessa verificação, outros pontos interessantes de investigação emergem, como o uso de equações simultâneas ou de modelos de espaço-estado.

\section{Referências Bibliográficas}

AMAZONAS, A.; BARROS, A. R. Manufactured exports from Brazil: determinants and consequences. Revista Brasileira de Economia, v. 50, n. 1, p. 73100, 1996.

BARLOW, C; JAYASURIYA, S.; SUAN TAN, C. The World Rubber Industry, Routledge, London, England, 1994. 
BRAGA, H. C.; ROSSI, J. W. A dinâmica da balança comercial no Brasil, 19701984. Revista Brasileira de Economia, v. 41, n. 2, p. 237-248, 1987.

BRITTO, G. Abertura Comercial e Reestruturação Industrial no Brasil: Um estudo dos coeficientes do comércio. Dissertação de mestrado. IE-Unicamp, Campinas, 2002.

BURGER, K.; SMIT, H.; VOGELVANG, B. Exchange rates and natural rubber prices, the effect of the Asian crisis, Working paper, Department of Econometrics, Economic and Social Institute, Faculty of Economics and Business Administration, Vrije University, The Netherelands, 2002.

CARDOSO, C.A.; PEREIRA, L.F.V.N; DIAS, H.B. Apreciação cambial recente e a evolução das exportações brasileiras: uma análise empírica. Textos de Economia, Florianópolis, v.9, n.2, p. 93-118, jul/dez 2006.

CARVALHO, A.; DE NEGRI, J. A. Estimação de equações de importação e exportação de produtos agropecuários para o Brasil (1977/1998). Rio de Janeiro: IPEA, Texto para Discussão nº 698, 2000.

CASTRO, A. S.; CAVALCANTI, M. A. F. H. Estimação de equações de exportação e importação para o Brasil - 1955/95. Pesquisa e Planejamento Econômico, v. 28, n. 2, p. 1-68, 1998.

DURBIN, J.; KOOPMAN, S.J. Time Series Analysis by State Space Methods, Oxford Statistical Science Series, Oxford University Press, 2001.

ENGLE, R. F; GRANGER, C. W. J. Cointegration and error-correction: representation, estimation, and testing. Econometrica, v. 55, p. 251-276, 1987.

GAMERO, A.H.; PEROZZI, M.B. Perspectivas para o Brasil no Cenário Internacional da Borracha Natural, disponível em http://www.heveabrasil.com, Outubro/2007.

GAMERO, A.H.; SARETTA, C.B. Regulamentação pública e conduta das firmas no sistema agroindustrial da borracha natural entre 1997 e 2000. Rev. Econ. Sociol. Rural, vol.40, no.3, Brasília, 2002.

GREGORY, A.W.; HANSEN, B.E. Residual-based tests for cointegration in models with regime shifts, Journal of Econometrics, 70, pp. 99-126, 1996.

HAMILTON, J.D. A New Approach to the Economic Analysis of Nonstationary Time Series and the Business Cycle, Econometrica, v. 57, p. 357-384, 1989.

. A quasi-Bayesian approach to estimating parameters for mixtures of normal distributions, Journal of Business and Economic Statistics, 9, 27-39, 1991. 
Estimativa de um Modelo não Linear para as

Exportações Brasileiras de Borracha no Período 1992-2006

. Specification testing in Markov-Switching time series models, Journal of Econometrics, 70, 127-157, 1996.

HANSEN, B.E. The likelihood ratio test under non-standard conditions: Testing the Markov switching model of GNP, Journal of Applied Econometrics, 7, S61-S82, 1992.

HATANAKA, M. Time Series Based Econometrics - Unit roots and cointegration - Advanced texts in econometrics, Oxford University Press, 2003.

HURLEY, P.E. History of Natural Rubber, Journal of Macromolecular Science, Part A, v.15, n.7, p. 1279-1287, 1981.

HYLLEBERG, S.; ENGLE, R. F.; GRANGER, C. W. J.; YOO, B. S. Seasonal integration and cointegration. Journal of Econometrics, 44, p. 215-238, 1990.

INTERNATIONAL RUBBER STUDY GROUP, Rubber Statistical Bulletin, 2009.

JOHANSEN, S. Statistical analysis of cointegration vectors. Journal of Economic Dynamics and Control, n. 12, p. 231-254, 1988.

KANNEBLEY JR., S. Exchange rate pass-through: uma análise setorial para as exportações brasileiras (1984-1997), Economia Aplicada, v. 4, n. 3, p. 435-463, 2000.

KROLZIG, H-M.; MARCELliNO, M.; MIZON, G.E. A Markov-Switching Vector-Equilibrium correction model of the UK labour market, Working Paper, Department of Economics, Oxford, 2000.

MIRANDA, J.C. "Abertura comercial, reestruturação industrial e exportações brasileiras na década de 1990". Texto para discussão no 829, IPEA, Rio de Janeiro, 2000.

MORAES, P. B. Uma nota sobre as importações brasileiras de produtos manufaturados. Revista de Econometria, ano VI, n. 2, p. 69-82, 1986.

MORAIS, I.A.C.; BARBOSA, A.E. Equações de Oferta e Demanda por Exportações do Setor de Calçados, 1985/2003.Análise Porto Alegre v. 17 n. 1 p. 67-90 jan./jul. 2006

MORAIS, I.A.C.; PORTUGAL. M.S. A markov-switching model for the Brazilian Demand for Imports: Analyzing the import substitution process in Brazil. Revista de Econometria, Rio de Janeiro, v.25, n.2, p.173-219, 2005.

MORCELI, P. Borracha Natural - Situação Atual e Perspectivas. Estudos da Companhia Nacional de Abastecimento - CONAB, 2003.

MOURA, G; Da SILVA, S. Is there a Brazilian J-Curve? Economic Bulletin, vol.6, n.1, p.1-17, 2005.

PERRON, P. Further evidence on breaking trend functions in macroeconomic variables. Journal of Econometrics, v. 80, p. 355-385, 1997. 
PORTUGAL, M. S. A instabilidade dos parâmetros nas equações de exportação brasileiras. Pesquisa e Planejamento Econômico, v. 23, n. 2, p. 313-348, 1993.

RIBEIRO, L.S.L. Dois ensaios sobre a Balança Comercial Brasileira: 1999/2005, Dissertação de Mestrado, PUC-Rio, 2006.

RUUD, P.A. Extension of estimation methods using the EM-algorithm, Journal of Econometrics, 49, 305-341, 1991.

SAMONEK, F. A borracha vegetal extrativa na Amazônia: Um estudo de caso dos novos encauchados de vegetais no Estado do Acre. Dissertação de Mestrado, Universidade Federal do Acre, Rio Branco, 2006.

SOEPENDI, I.Y. Indonesian natural rubber: an econometric analysis of its export supply and foreign import demand, Michigan State University Thesis, Department of Agricultural Economics, 1993. 